\title{
The in Planta Effective Concentration of Oxytetracycline Against 'Candidatus Liberibacter asiaticus' for Suppression of Citrus Huanglongbing
}

\author{
Jinyun Li, Zhiqian Pang, Shuo Duan, Donghwan Lee, Vladimir G. Kolbasov, and Nian Wang ${ }^{\dagger}$ \\ Citrus Research and Education Center, Department of Microbiology and Cell Science, Institute of Food and Agricultural Sciences, University of \\ Florida, Lake Alfred, FL 33850 \\ Accepted for publication 26 July 2019.
}

\begin{abstract}
Huanglongbing (HLB) or greening currently is the most devastating citrus disease worldwide. The fastidious phloem-colonizing bacterium 'Candidatus Liberibacter asiaticus' (CLas) is the causal agent of citrus HLB in Florida. Bactericides containing the active ingredient oxytetracycline (OTC) have been used in foliar spray to control citrus HLB in Florida since 2016. However, the minimum concentration of OTC required to suppress CLas in planta remains unknown. We developed a new method for evaluating the effects of OTC treatment on CLas titers in infected plants and determined the relationship between OTC residue levels and control levels achieved for CLas using mathematical modeling in greenhouse and field experiments. In both greenhouse and field, OTC spray did not reduce the titers of CLas, and it produced undetectable or mild levels of OTC residue in leaves within 7 days postapplication (DPA). In greenhouse, OTC injection at $0.05 \mathrm{~g}$ per tree decreased CLas titers to an undetectable level (cycle threshold value $\geq 36.0$ ) from 7 to 30 DPA and produced a residue level of OTC at 0.68 to $0.73 \mu \mathrm{g} / \mathrm{g}$ of fresh tissue over this period. In the field, OTC injection at $0.50 \mathrm{~g}$ per tree resulted in the decline of CLas titers by $1.52 \mathrm{log}$
\end{abstract}

ABSTRACT

Huanglongbing (HLB), also called citrus greening disease, is currently the most serious disease affecting the global citrus industry (Wang 2019). HLB has become well established in major citrus-producing regions, including Asia and the Americas, where it has caused enormous economic losses, and it continues to spread worldwide (Blaustein et al. 2018; Wang et al. 2017a). HLB is associated with three gram-negative, phloem-residing, and unculturable bacterial species of Candidatus Liberibacter: 'Candidatus Liberibacter asiaticus' (CLas) in Asia, Africa, and the Americas; 'Candidatus Liberibacter africanus' in Africa; and 'Candidatus Liberibacter americanus' in Brazil (Bové 2006; Gottwald et al. 2007; Wang et al. 2017a). Among them, CLas is the most prevalent species worldwide (Bové 2006; Gottwald 2010; Wang et al. 2017a). Since it was first reported in Southeast Asia $>100$ years ago, HLB has spread to most commercial citrus production areas in the world, except the Mediterranean region and Australia (Wang et al. 2017a). HLB has become endemic in Florida. Between 2005 and 2016, the estimated losses to the Florida citrus industry caused by HLB exceeded $\$ 8$ billion (Singerman et al. 2018). In 2012, HLB was also

${ }^{\dagger}$ Corresponding author: N. Wang; nianwang@ufl.edu

Funding: This work was supported by the Citrus Research and Development Foundation and the Florida Department of Agriculture and Consumer Service Citrus Initiative Program.

*The $\boldsymbol{e}$-Xtra logo stands for "electronic extra" and indicates that one supplementary figure and three supplementary tables are published online.

The author(s) declare no conflict of interest.

(C) 2019 The American Phytopathological Society reduction from 14 to $60 \mathrm{DPA}$, with residue levels of OTC at 0.27 to $0.33 \mu \mathrm{g} / \mathrm{g}$ of fresh tissue. In both trials, a first-order compart model of OTC residue dynamics in leaves of trunk-injected trees was specified for estimating the retention of effective concentrations. Furthermore, nonlinear modeling revealed significant positive correlations between OTC residue levels in leaves and the control levels for CLas achieved. The results suggested that the minimum concentrations of OTC required to suppress CLas populations in planta to below the detection limit are 0.68 and $0.86 \mu \mathrm{g} / \mathrm{g}$ and that the minimum concentrations of OTC required for initial inhibition of CLas growth in planta are $\sim 0.17$ and $\sim 0.215 \mu \mathrm{g} / \mathrm{g}$ in leaf tissues under greenhouse and field conditions, respectively. This finding highlights that a minimum concentration of OTC should be guaranteed to be delivered to target CLas in infected plants for effective control of citrus HLB.

Keywords: antibiotics, bacteriology, bactericides, citrus, disease control, Huanglongbing, Liberibacter, minimum inhibitory concentration, oxytetracycline detected in California and Texas (da Graça et al. 2015; Kumagai et al. 2013).

In Asia and the Americas, CLas is transmitted to citrus by the Asian citrus psyllid (ACP; Diaphorina citri 'Kuwayama') during sap feeding, where it then colonizes the phloem sieve elements, eventually leading to disease symptoms. Infected trees exhibit leaf mottling, deformed and discolored fruits, premature fruit drop, root loss, and eventually, tree mortality (Bové 2006; Gottwald 2010; Johnson et al. 2014; Wang et al. 2017b). Currently, all commercial citrus cultivars can be infected by CLas (Clark et al. 2018; Wang et al. 2017a).

Currently, there are no practical cures for HLB (National Academies of Sciences, Engineering, and Medicine 2018; Wang 2019). Palliative and preventive measures are currently being used for HLB disease management, including control of the insect vector ACP, enhanced foliar nutrient programs, and eradication of symptomatic trees as well as the use of certified CLas-free seedlings for new plantings (Blaustein et al. 2018; Wang et al. 2017a). Application of insecticides combined with foliar nutritional spray has kept ACP populations at low levels, slowed spread of the disease, and maintained yield potential in orchards with high incidence of HLB, but it has not prevented the spread of HLB to new plantings (Stansly et al. 2014; Tansey et al. 2017). Extensive application of insecticides raised the concerns of altering the balance between pests and their natural enemies, causing secondary pest outbreaks, pest resurgence, and selection of insecticideresistant populations (Kruse et al. 2017; Tiwari et al. 2011). Eradication to remove sources of inoculum may prevent HLB from becoming endemic in newly infected citrus-producing areas, such as California, but it has no or only limited effect in preventing spread of the disease in HLB-endemic regions, such as Florida, because of the high incidence of disease and the long, variable asymptomatic 
incubation period (Lee et al. 2015). Several new control tactics, such as chemotherapy (Zhang et al. 2014, 2019), thermotherapy (Ehsani et al. 2016; Zhang et al. 2019), and transgenic citrus (Dutt et al. 2015; Zou et al. 2017), are in the early stages of development, and they are likely years away from application in the field. Therefore, better options to reduce the damage and losses caused by HLB are urgently needed.

Trunk injection of antibiotics has been tested to control plant diseases, including citrus HLB (Aćimović et al. 2015; Puttamuk et al. 2014; Shin et al. 2016). Trunk injection is a target-precise method for efficient delivery of compounds directly into plants, with less environmental exposure compared with foliar spray (Aćimović et al. 2015). Several field studies have focused on trunk injection of antibiotics in HLB management. Trunk injections of HLB-affected citrus with penicillin alone or combined with ampicillin, streptomycin, and/or tetracycline were effective at reducing and suppressing the CLas bacterium population and HLB symptoms in the field (Puttamuk et al. 2014; Shin et al. 2016). Oxytetracycline (OTC) injected alone or combined with streptomycin provided significant suppression of CLas populations in CLas-infected trees and prevented further tree decline by promoting symptomless new growth under field conditions ( $\mathrm{Hu}$ and Wang 2016; Hu et al. 2018). Currently, none of the antibiotics tested in those studies have been registered for truck injection of citrus trees, although both OTC and streptomycin have been approved for foliar sprays of citrus trees in Florida under an emergency Section 18c exemption in 2016.

Large-scale field trials of OTC and streptomycin treatments via foliar spray have been initiated in various citrus groves in Florida since 2016, and they are still ongoing (National Academies of Sciences, Engineering, and Medicine 2018). The data currently available from some of these trials have indicated that OTC and/or streptomycin spray treatments have medium to low efficacy under high disease pressure as well as inconsistent results depending on citrus cultivar, tree age, application timing, adjuvants mixed, and location-specific climate conditions (National Academies of Sciences, Engineering, and Medicine 2018). These observations have raised many questions regarding the use of OTC for the control of citrus HLB. Most questions concern the effective concentration of antibiotics in the trees. Therefore, this study aimed to address these questions using OTC as a model in greenhouse and field experiments. The objectives of this study were to (i) estimate OTC concentrations in citrus leaves after application via foliar spray or trunk injection, (ii) determine the effects of OTC treatment on CLas titers in leaves, and (iii) relate OTC residue levels in leaf tissues with the control level for CLas achieved.

\section{MATERIALS AND METHODS}

Greenhouse study. The experiments were performed in a quarantine greenhouse at the Citrus Research and Education Center in Lake Alfred, Florida, in 2018. Three-year-old Valencia sweet orange trees on Swingle rootstocks (Citrus sinensis [L.] Osbeck) on Swingle citrumelo (Citrus paradisi Macf 'Duncan' grapefruit $\times$ Poncirus trifoliata [L.] Raf) grown in black plastic pots $(20-\mathrm{cm}$ diameter and $40-\mathrm{cm}$ high) were used for the tests. The pots contained a blend of $50 \%$ sand and $50 \%$ potting media (Fafard Professional Potting Mix; Sun Gro). The trees were graft inoculated with CLas in 2016, and they were confirmed to be HLB positive using quantitative PCR (qPCR) assays before injection. The average height and diameter of the stems at $15 \mathrm{~cm}$ above the soil surface were $\sim 0.9 \mathrm{~m}$ and $\sim 3.2 \mathrm{~cm}$, respectively. OTC was applied to trees via foliar spray and trunk injection. For the spray experiment, two-tree plots were arranged in a randomized complete block design (RCBD) with two treatments and 10 replicates. Treatments consisted of an untreated control (sprayed with water) and OTC (FireLine $17 \mathrm{WP}$; Agrosource, Inc.) applied at the maximum label rate $(1,828 \mathrm{~g} / \mathrm{ha}$ per application) for citrus trees based on 2,964 trees per hectare (1,200 trees per acre). A single OTC application was made by spraying $200 \mathrm{ml}$ of OTC solution (2.95 g/liter of FireLine 17 WP: 0.50 g/liter active ingredient OTC) with $1.25 \mathrm{ml} /$ liter of Cohere nonionic spreader-sticker adjuvant (Helena $\mathrm{Ag}$ ) onto each tree at $\sim 400 \mathrm{kPa}$ with a handheld pump sprayer. This pressure resulted in a fine mist and was sufficient to produce runoff from the leaves. For trunk injection experiments, plots consisting of three trees were arranged in an RCBD with three treatments and five replicates. Treatments consisted of an untreated control (injected with water) and two different concentrations $(0.025$ and $0.05 \mathrm{~g}$ per tree) of OTC. The greenhouse was maintained at $25^{\circ} \mathrm{C}\left( \pm 5^{\circ} \mathrm{C}\right)$ with water-cooling pads and ventilation fans, and no artificial light was equipped.

Field study. In 2018, a field study was conducted at commercial groves in Auburndale, Florida, to evaluate the effect of OTC treatment by foliar spray and trunk injection. The experiments were conducted with Hamlin sweet orange (C. sinensis [L.] Osbeck) on Swingle citrumelo (C. paradisi Macf 'Duncan' grapefruit $\times$ $P$. trifoliata [L.] Raf) rootstock. The trees were planted at a density of 240 trees per acre (593 trees per hectare) in 2013. They were 1.8to $2.2-\mathrm{m}$ tall and $1.5-$ to $1.8-\mathrm{m}$ wide. The groves was naturally infected by CLas, and all trees received standard commercial care, including regular irrigation, fertilization, and pest management practices that were continued throughout the trial, but no bactericide application. For OTC spray experiment, two-tree plots were arranged in an RCBD with two treatments and 10 replicates. Treatments consisted of an untreated control (sprayed with water) and OTC (FireLine $17 \mathrm{WP}$ ) applied at the maximum label rate $(1,828 \mathrm{~g} / \mathrm{ha}$ per application) for citrus trees based on 346 trees per hectare (140 trees per acre). Three OTC applications were made by spraying 1.8 liters of OTC solution $(2.95 \mathrm{~g} /$ liter of FireLine $17 \mathrm{WP}$ : $0.50 \mathrm{~g} /$ liter active ingredient, OTC) with $1.25 \mathrm{ml} /$ liter of Cohere nonionic spreader-sticker adjuvant onto each tree at $400 \mathrm{kPa}$ during spring (early March), summer (middle May), and late summer (late August). For trunk injection experiment, three-tree plots were arranged in an RCBD with five replicates. Treatments were an untreated control (injected with water) and two concentrations $(0.25$ and $0.50 \mathrm{~g}$ per tree) of OTC. Trunk diameter at $15 \mathrm{~cm}$ above the bud union was $\geq 10 \mathrm{~cm}$ for all trees in the experiment. Two days before injection, all experimental trees were confirmed to be HLB positive, and CLas titers were determined using qPCR (Trivedi et al. 2009; Wang et al. 2006).

OTC injection. The OTC used for tree injection was laboratorygrade OTC (OTC hydrochloride $\geq 95 \%$; Sigma-Aldrich). The desired amount of OTC was dissolved in methanol and diluted in sterile distilled water (SDW) to the appropriate injection volume depending on tree size: $20 \mathrm{ml}$ per tree for greenhouse tests and $500 \mathrm{ml}$ per tree for field trials. In the greenhouse, a Chemjet tree injector (Chemjet Trading) containing a coil spring pressing injected the treatment into the tree over a $24-\mathrm{h}$ period. The tip of the injector was fitted into a 4.2-mm-diameter hole $\sim 25-\mathrm{mm}$ deep drilled in the trunk just below the graft region about $15 \mathrm{~cm}$ above the soil surface. SDW was injected into control trees. In field experiments, OTC was applied with Tree I.V. (Arborjet Inc.) at the recommended pressure $(\sim 345 \mathrm{kPa})$ on sunny days in March 2018. Briefly, a hole on the trunk was drilled $20 \mathrm{~cm}$ below the first branch to a depth of 2 to $3 \mathrm{~cm}$ using a 7.14-mm drill bit; a No. 3 Arborplug was set into the hole for proper seal with Arborplug setter and a rubber hammer. The area surrounding the drilling site was sprayed with $20 \mathrm{ml}$ of Mefenoxam solution (337.5 ml/liter of RidomilGoldSL; Syngenta Crop Protection) at the maximum label rate (2,337 ml/ha per application) for citrus based on 346 trees per hectare to prevent infection by Phytophthora spp. Each injection required 24 to $48 \mathrm{~h}$ to place the treatment volume in the tree. Control trees were injected with SDW.

OTC concentration in citrus trees. OTC concentrations in leaf samples from greenhouse trees were estimated at 0 (preapplication), 2, 4, 7, 14, 21, and 28 days post-application (DPA) for foliar 
spray experiments and 0 (preinjection), 4, 7, 14, 30, 60, 90, 120, and 150 DPA for injection experiments. Three leaves were sampled from each tree in each of three branches growing in different directions, and they were immediately taken to the laboratory for OTC concentration estimation. The concentrations of OTC in leaves of field trees were tested on 0 (preapplication), 2, 4, 7, 14, 21 , and 28 DPA for foliar spray experiments and 0 (preinjection: 2 days before injection), 4, 7, 14, 30, 60, 90, 120, and 150 DPA. Eight young, fully expanded leaves were collected from four branches (two leaves each) per tree and placed in a plastic bag at each sampling date. During harvest (December 2018), five fruits from each injected tree were randomly selected for OTC residue assays. Samples were transported to the laboratory in a cooler with ice packs for OTC concentration estimation using HPLC assays as described below.

Extraction and determination of OTC concentrations using highperformance liquid chromatography (HPLC) assays in leaf tissues were performed as described by Hu and Wang (2016), except for the preparation of plant tissue. Briefly, midribs of the leaf samples were collected, pooled, and used for OTC extraction. Leaf samples from OTC spray treatments were rinsed for $10 \mathrm{~s}$ under running distilled water before collection of midribs to remove the superficial residue of OTC. After being chopped into 0.5-mm-long pieces with sterile razor blades, about $500 \mathrm{mg}$ of midrib tissues were placed in 2-ml screw cap tubes (Fisher Scientific), treated in liquid nitrogen, and pulverized with a Tissuelyser II (QIAGEN). The pulverized tissue was placed on a piece of wax paper and mixed again with a toothpick. From this tissue, 100-mg (DNA isolation) and 200-mg (OTC extraction) aliquots were sampled into new Eppendorf tubes. OTC extraction and quantification followed methods of $\mathrm{Hu}$ and Wang (2016). Briefly, OTC was extracted with a pH 4.0 $\mathrm{Na}_{2}$ EDTAMacIlvaine buffer; then, the OTC extract was cleaned up using an solid-phase extraction (SPE) cartridge (Bond Elut C18 OH 100 $\mathrm{mg} / \mathrm{ml}$; Agilent) and analyzed with an Agilent 1260 Infinity Quaternary Liquid Chromatography system. OTC was separated in an Eclipse plus C18 column (Agilent; $100 \times 4.6 \mathrm{~mm}$ ) and detected with a fluorescence detector at $390-n m$ excitation and 512-nm emission wavelengths. The mobile phase contained buffer ( $\mathrm{pH} 7.3$ ) of $30 \%$ methanol and $70 \%$ aqueous solution of $0.035 \mathrm{M}$ calcium chloride, $0.025 \mathrm{M}$ disodium EDTA, and $0.075 \mathrm{M}$ sodium acetate. The flow rate was $0.8 \mathrm{ml} / \mathrm{min}$, and the autosampler was configured to inject 20- $\mu$ l aliquots of samples.

DNA extraction and real-time qPCR assays for evaluation of CLas titers in citrus trees. DNA was isolated from macerated leaf midribs using the Wizard Genomic DNA purification kit (Promega) following the manufacturer's recommendations. The air-dried DNA pellet was dissolved in 50 to $100 \mu \mathrm{l}$ of DNA rehydration solution (Promega) and kept at $-20^{\circ} \mathrm{C}$. The real-time qPCR was performed with the CLas-specific primer-probe set "CQULA04F-CQULAP10-CQULA04R" (Trivedi et al. 2009; Wang et al. 2006) using the ABI PRISM 7500 sequence detection system (Applied Biosystems). The 20- $\mu$ l TaqMan PCR reaction mixture contained $10 \mu \mathrm{l}$ of $2 \times$ Quantitect probe PCR master mix (Qiagen), $500 \mathrm{nM}$ each primer, $200 \mathrm{nM}$ probe, and $100 \mathrm{ng}$ of DNA template. The qPCR amplification setting included $95^{\circ} \mathrm{C}$ denaturation for $15 \mathrm{~min}$ followed by 40 cycles of $94^{\circ} \mathrm{C}$ for $15 \mathrm{~s}$ and $60^{\circ} \mathrm{C}$ for $1 \mathrm{~min}$. All DNA samples were run in triplicate. The cycle threshold $(\mathrm{Ct})$ values were obtained by adjusting threshold to the recommended level of 0.02 , and they were converted to the estimated bacterial titers with a standard curve as described by $\mathrm{Li}$ et al. (2016). When the recorded $\mathrm{Ct}$ is $\geq 36$.0, the testing leaf samples do not show HLB symptoms, and CLas is generally considered to be nondetectable ( $\mathrm{Li}$ et al. 2006; Puttamuk et al. 2014; Zhang et al. 2011). Here, we defined $\mathrm{Ct} \geq 36.0$ as $100 \%$ control of HLB.

Estimation of the relative level of control for CLas achieved by OTC application. The titers of CLas at posttreatment relative to the titers at pretreatment were used to evaluate the change of CLas titer in response to OTC treatment. Mean titers of
CLas in pre- and posttreatment samples were used to estimate the response ratio $(R)$ as

$$
R=\frac{T_{t r}}{T_{0}}
$$

where $T_{t r}$ is the mean titer of CLas posttreatment and $T_{0}$ is the mean titer of CLas pretreatment. $R$ is directly related to the percentage change $(C)$ of CLas titer as

$$
C=\frac{T_{0}-T_{t r}}{T_{0}} \times 100=\left(1-\frac{T_{t r}}{T_{0}}\right) \times 100=(1-R) \times 100
$$

$C$ contains the same information found in $R$. $R$ (or $C$ ) could be a useful measure of antibiotic effectiveness for the control of CLas (Hu et al. 2018). However, the logarithm of $R$ (or $C$ ) is more suitable for statistical analyses than $R$ (or $C$ ), because the logarithm linearizes the ratio metric, treating deviations of the numerator and denominator equally, and it typically is closer to a normal distribution than $R$ (or $C$ ) (Paul et al. 2007). The natural $\log$ of $R$ $(L)$, where

$$
L=\ln (R)=\ln \left(\frac{T_{t r}}{T_{0}}\right)=\ln \left(T_{t r}\right)-\ln \left(T_{0}\right)
$$

is termed the effect size, and it is a commonly reported measure of material effectiveness for plant disease control (Ngugi et al. 2011; Paul et al. 2007). As mentioned, we defined the Ct of qPCR assay $\geq 36.0$ as $100 \%$ control. Our equation developed to quantify CLas titers in citrus, however, estimates titers of CLas at $\mathrm{Ct}=36.0$ $\left(T_{C t 36}\right)$ equal to $2.16 \times 10^{3}$ cells per gram of tissue. Therefore, for practical reasons, we designated the effect size at $\mathrm{Ct}=36.0$ achieved by OTC treatment $\left(L_{C t 36}\right)$ as the metric of a complete control of CLas:

$$
L_{C t 36}=\ln \left(T_{C t 36}\right)-\ln \left(T_{0}\right)
$$

Consequently, a relative level of control for CLas $(R L)$ at $\mathrm{Ct}<36.0$ achieved by OTC treatment could be computed by normalizing the effect size of OTC treatment at $\mathrm{Ct}<36.0$ against the effect size at $\mathrm{Ct}=36.0$ as

$$
R L(\%)=\frac{L}{L_{C t 36}} \times 100=\frac{\ln \left(T_{t r}\right)-\ln \left(T_{0}\right)}{\ln \left(T_{C t 36}\right)-\ln \left(T_{0}\right)} \times 100
$$

at $\mathrm{Ct} \geq 36.0$ (i.e., there is a negative detection of CLas, $T_{t r}$ is equivalent to $T_{C t 36}$, and the $R L$ is $100 \%$ ).

Determination of minimum inhibitory concentration of OTC against cultured close relative bacteria of CLas. The minimum inhibitory concentrations (MICs) of OTC against Agrobacterium tumefaciens C58, Sinorhizobium meliloti 1021, and Liberibacter crescens BT-1 were determined using the broth microdilution method (Andrews 2001). Briefly, bacterial strains were grown to exponential phase in Luria broth (LB), tryptoneyeast extract (TY) (Beringer 1974), and BM-7 (Fagen et al. 2014) media for A. tumefaciens C58, S. meliloti 1021, and L. crescens BT-1, respectively, at $28^{\circ} \mathrm{C}$ with shaking at $180 \mathrm{rpm}$. The cultures were standardized to an optical density $(\mathrm{OD})_{600 \mathrm{~nm}}=0.03(0.5 \times$ $10^{8} \mathrm{CFU} / \mathrm{ml}$ ) in respective medium, and then, they were aliquoted into wells of a 96-well plate, with $180 \mu \mathrm{l}$ per well. The initial test concentrations of OTC were diluted (1:10) in the culture $(20 \mu \mathrm{l}$ of OTC added in $180 \mu \mathrm{l}$ of culture) and incubated at $28^{\circ} \mathrm{C}$ under stationary conditions. The cultures were evaluated at $24 \mathrm{~h}, 48 \mathrm{~h}$, and 14 days at $\mathrm{OD}_{600 \mathrm{~nm}}$ for $A$. tumefaciens C58, S. meliloti 1021 , and $L$. crescens BT-1, respectively. The lowest concentration resulting in no visible growth compared with the control samples was defined as the MIC for the tested bacterium. Bacterial suspension without OTC treatment and corresponding medium without bacterial culture were used as positive and negative controls of bacterial growth, respectively. All tests were performed in eight replicate wells and repeated three times. 
Data analysis. Data were subjected to repeated measures analysis of variance with the MIXED procedure in SAS V9.4 (SAS Institute Inc). Evaluated effects include treatment, time since application, and the interaction between treatment and time since application on CLas titers. The first-order autoregressive covariance structure option in the MIXED procedure was selected based on the Akaikei and Bayesian information criteria. Before analysis, CLas titers were $\log _{10}$ transformed to satisfy assumptions of normality and homoscedasticity. When treatment effects were significant $(P<0.05)$, pairwise comparisons were made using the LSMEANS statement with the Tukey honestly significant difference $(\alpha=0.05)$ adjustment for mean separation. When interactions of factors were significant $(P<0.05)$, the SLICE option of the LSMEANS statement was used to compare levels of one factor within levels of another factor.

A first-order compartment model that explains the distribution and elimination of a drug after uptake into a living organism, taking dose of the drug, absorption rate, and degradation/elimination rate as parameters (SAS), was used to describe the dynamics of OTC residue in citrus leaf tissues after trunk injection. In addition, nonlinear regression analyses were performed to determine the relationship between OTC residue levels in leaf tissues and the detectability of CLas ( $\mathrm{Ct}$ values) as well as the relationship between OTC residue levels and the relative level of control for CLas achieved by a treatment. The analysis was conducted using the NLIN procedure in SAS.

\section{RESULTS}

Impact of OTC treatment on CLas titers in HLBdiseased trees. In greenhouse, after a foliar spray of OTC, there were no significant effects of treatment $(F=0.04 ; \mathrm{df}=1,108 ; P=$ $0.8489)$ or time since application $(F=1.91$; df $=6,108 ; P=$ 0.0849 ) on CLas titers over the 4-week study duration. OTC spray did not show a significant impact on CLas populations in HLBdiseased trees compared with the water-sprayed control at various time points after treatment application (Supplementary Table S1). However, after trunk injection of OTC, there were highly significant effects of treatment $(F=4295.61$; df $=2,96 ; P<$ $0.0001)$ and time after application $(F=265.90$; df $=8,96 ; P<$ $0.0001)$ on CLas titers. OTC injection significantly reduced CLas

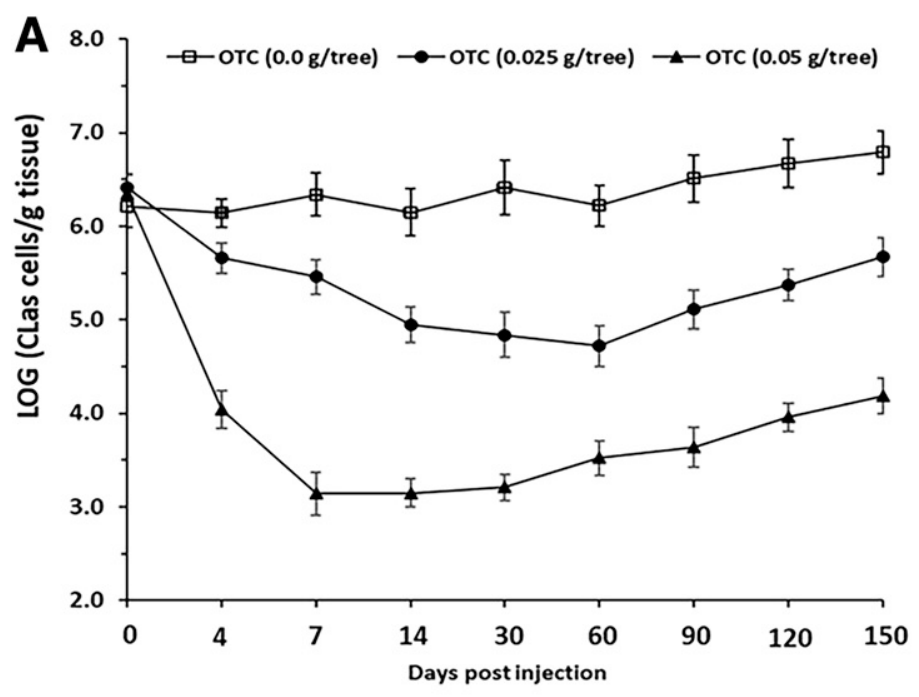

titers in HLB-diseased trees starting from 4 days postinjection (DPI) (Fig. 1A). In the control group, CLas titers were consistently higher than in OTC treatments, with a mean of $2.87 \times 10^{6} \mathrm{CFU} / \mathrm{g}$ of fresh tissue over the 5 -month duration of the study. OTC treatments significantly reduced CLas titers $(P<$ 0.0001 ) from $4 \mathrm{DPI}$ onward, with a mean of $4.48 \times 10^{3} \mathrm{CFU} / \mathrm{g}$ of fresh tissue for OTC injected at $0.05 \mathrm{~g}$ per tree and $1.81 \times 10^{5}$ $\mathrm{CFU} / \mathrm{g}$ of fresh tissue for OTC injected at $0.025 \mathrm{~g}$ per tree. There was a significant interaction between treatment and time after application $(F=121.41$; df $=16,96 ; P<0.0001)$ on CLas titers. The analysis of sampling time effect by the SLICE option and pairwise comparisons of the sampling times within each treatment showed that there was a significant decline in CLas titers over time for OTC injected at $0.025 \mathrm{~g}$ per tree $(F=72.37$; df $=8,96 ; P<0.0001)$ and $0.05 \mathrm{~g}$ per tree $(F=427.54 ; \mathrm{df}=8,96 ; P<$ $0.0001)$. In contrast, CLas titers in the control group increased with sampling time $(F=17.63 ; \mathrm{df}=8,96 ; P<0.0001)$.

In the field, OTC sprays did not show a significant impact on CLas titers in HLB-diseased trees $(F=0.15$; df $=1,108 ; P=$ 0.7058 for spray in March 2018; $F=0.93 ; \mathrm{df}=1,108 ; P=0.3477$ for spray in May 2018; $F=0.32 ; \mathrm{df}=1,108 ; P=0.5779$ for spray in August 2018) compared with the untreated control at various time points after each treatment application (Supplementary Table S2). However, after trunk injection of OTC, there were highly significant effects of treatment $(F=324.45$; df $=2,96 ; P<$ $0.0001)$ and time since application $(F=28.48 ; \mathrm{df}=8,96 ; P<$ $0.0001)$ on CLas titers. Trunk injection of OTC significantly reduced CLas titers in HLB-diseased trees starting from 4 DPI (Fig. 1B). CLas titers of the control group were consistently higher $(P<0.0001)$ than those of OTC treatments, with means of $3.37 \times$ $10^{7} \mathrm{CFU} / \mathrm{g}$ of fresh tissue for the control, $1.24 \times 10^{6} \mathrm{CFU} / \mathrm{g}$ of tissue for OTC injected at $0.5 \mathrm{~g}$ per tree, and $6.01 \times 10^{6} \mathrm{CFU} / \mathrm{g}$ of tissue for OTC injected at $0.25 \mathrm{~g}$ per tree over the 5 -month duration of the study. There was a significant interaction between treatment and time since application $(F=17.39 ; \mathrm{df}=16,96 ; P<0.0001)$ on CLas titers. The analysis of sampling time effect by the SLICE option and pairwise comparisons showed that there was a significant decline in CLas titers over time for OTC injected at 0.25 g per tree $(F=13.05 ; \mathrm{df}=8,96 ; P<0.0001)$ and $0.50 \mathrm{~g}$ per tree $(F=48.61 ; \mathrm{df}=8,96 ; P<0.0001)$. In contrast, CLas titers in the control group increased with sampling time $(F=4.77 ; \mathrm{df}=8,96$; $P<0.0001)$.

Fig. 1. The 'Candidatus Liberibacter asiaticus' (CLas) bacterial titers in leaf midribs of Huanglongbing-affected citrus plants at various time points after the injection of oxytetracycline (OTC). A, CLas titers in Valencia sweet orange (Citrus sinensis [L.] Osbeck) trees in a greenhouse at 0 (pretreatment), 4, 7, 14, 30, 60, 90, 120, and 150 days after the injection of OTC at 0.0, 0.025, and $0.05 \mathrm{~g}$ per tree in a 20-ml solution. B, CLas titers in Hamin sweet orange $(C$. sinensis [L.] Osbeck) trees in a grove in Auburndale, Florida, U.S.A., at 0 (pretreatment), 4, 7, 14, 30, 60, 90, 120, and 150 days after the injection of OTC at 0, 0.25 , and 0.50 g per tree. CLas titers represent means, and error bars represent standard deviation $(n=5)$ on logarithmic scale. 
OTC concentration in citrus trees. In the greenhouse, OTC residues in leaf tissues after foliar spray were detected at a level of about $0.07 \mu \mathrm{g} / \mathrm{g}$ of fresh tissue from 2 to 4 DPA and then, declined steadily over the test period (Table 1). At 14 DPA, the OTC residues in leaf tissues were undetected. No OTC residues were detected in the samples of water-sprayed control over the test period. After trunk injection, OTC levels in leaf tissues rapidly increased during the first week posttreatment, with peak residues of OTC occurring at 7 DPA (Fig. 2A). At the injection rate of $0.05 \mathrm{~g}$ per tree, OTC concentration peaked above $0.70 \mu \mathrm{g} / \mathrm{g}$ of fresh tissue at 7 DPA and remained at similar levels until 14 DPA; then, declined steadily over the test period. At 5 months postinjection (end of experiment), leaf tissue OTC concentration still exceeded $0.40 \mu \mathrm{g} / \mathrm{g}$ of fresh tissue. A first-order compartment model $\left(Y=15.3 \times D \times\left(e^{-0.0038 x}-e^{-0.69 x}\right)\right)$ described the variation of OTC concentration in leaf tissue through time appropriately $\left(F=358.4 ; \mathrm{df}=3,8 ; P<0.0001 ; R^{2}=0.99\right)$ (Fig. 2A), where $Y$ is OTC concentration, $x$ is days postinjection, and $D$ is dose (grams per tree) of OTC injected. Based on this model, at the injection rate of $0.05 \mathrm{~g}$ per tree, the OTC residue concentration might be $0.39 \mu \mathrm{g} / \mathrm{g}$ in leaf tissues at 6 months postinjection in the greenhouse test. No OTC was detected in the pretreatment or untreated control leaf samples.

In the field trial, no OTC residues were detected in the OTC spray treatment or water-sprayed control leaf samples over the test period. After trunk injection, OTC levels in leaf tissues increased steadily during the first 2 weeks postinjection, with peak residues of OTC occurring at $14 \mathrm{DPA}$ (Fig. 2B). At the injection rate of $0.5 \mathrm{~g}$ per tree, OTC concentration reached a peak level above $0.30 \mu \mathrm{g} / \mathrm{g}$ of fresh tissue at 14 DPA and remained at similar levels for 2 weeks; then, it declined gradually over the test period. A first-order compartment model $\left(Y=0.69 \times D \times\left(e^{-0.0035 x}-e^{-0.26 x}\right)\right)$ could appropriately $(F=$ 639.4; $\left.\mathrm{DF}=3,8 ; P<0.0001 ; R^{2}=0.94\right)$ describe the variation of OTC concentration in leaf tissues through time (Fig. 2B), where $Y$ is OTC concentration, $x$ is days postinjection, and $D$ is dose (grams per tree) of OTC injected. Based on the model, at the injection rate of $0.5 \mathrm{~g}$ per tree, OTC might be detected at $0.184 \mu \mathrm{g} / \mathrm{g}$ in leaf tissue at 6 months postinjection. No OTC was detected in the pretreatment or untreated control leaf samples. During harvest, in fruit samples, the averaged OTC residues were 0.018 and $0.038 \mu \mathrm{g} / \mathrm{g}$ for trees injected with 0.25 and $0.50 \mathrm{~g}$ per tree, respectively (Table 2). No OTC was detected in the untreated control fruit samples.

Relationship between OTC residue levels and suppression of CLas titers in citrus leaves. In the greenhouse, the levels of OTC residues in leaf tissues significantly affected the titers of CLas in OTC-injected trees. A positive sigmoid relationship $\left(Y=24.2+15.8 \times e^{-e^{\left(\frac{0.28-x}{0.31}\right)}}\right)$ was obtained between the OTC residue concentration in citrus leaf tissues (midribs) and the detectability (Ct mean values) of CLas using qPCR $(F=352.3$; $\mathrm{df}=$ 3,$\left.11 ; P<0.0001 ; R^{2}=0.98\right)($ Fig. 3A). At the injection rate of $0.05 \mathrm{~g}$ per tree, from 4 to $30 \mathrm{DPA}$, the levels of OTC residues in leaf tissues exceeded $0.68 \mu \mathrm{g} / \mathrm{g}$ of fresh tissue (Fig. 2A), and that translated into observed $\mathrm{Ct}$ mean values $\geq 36.0$ (Fig. 3A), suggesting a negative detection for CLas. A positive sigmoid relationship $\left(Y=99.5 \times e^{-e^{(2.96-10.56 x)}}\right)$ was also obtained between the OTC residue levels in leaf tissues and the relative level of control for CLas

TABLE 1. Oxytetracycline (OTC) residual content in leaf tissues (midribs) of Valencia sweet orange (Citrus sinensis [L.] Osbeck) trees sprayed with $200 \mathrm{ml}$ of OTC at $0.50 \mathrm{~g} /$ liter or water in a greenhouse at the Citrus Research and Education Center, Lake Alfred, Florida, U.S.A.w

\begin{tabular}{lcccccc}
\hline & \multicolumn{5}{c}{ OTC content $(\mu \mathrm{g} / \mathrm{g}$ of fresh tissue) } \\
\cline { 2 - 6 } Treatment & $0 \mathrm{DPA}^{\mathrm{x}}$ & $2 \mathrm{DPA}$ & $4 \mathrm{DPA}$ & $7 \mathrm{DPA}$ & $14 \mathrm{DPA}$ & $21 \mathrm{DPA}$ \\
\hline OTC spray & $-\mathrm{y}$ & $0.073 \pm 0.013 \mathrm{a}^{\mathrm{z}}$ & $0.068 \pm 0.008 \mathrm{a}$ & $0.048 \pm 0.006 \mathrm{~b}$ & - \\
Water spray & - & - & - & - & - & - \\
\hline
\end{tabular}

${ }^{\mathrm{w}}$ Data shown are mean \pm standard deviation of five replicates $(n=5)$.

${ }^{x}$ DPA, days post-application.

y - , no detection.

$\mathrm{z}$ Means followed by different letters are significantly different $(P<0.05)$.
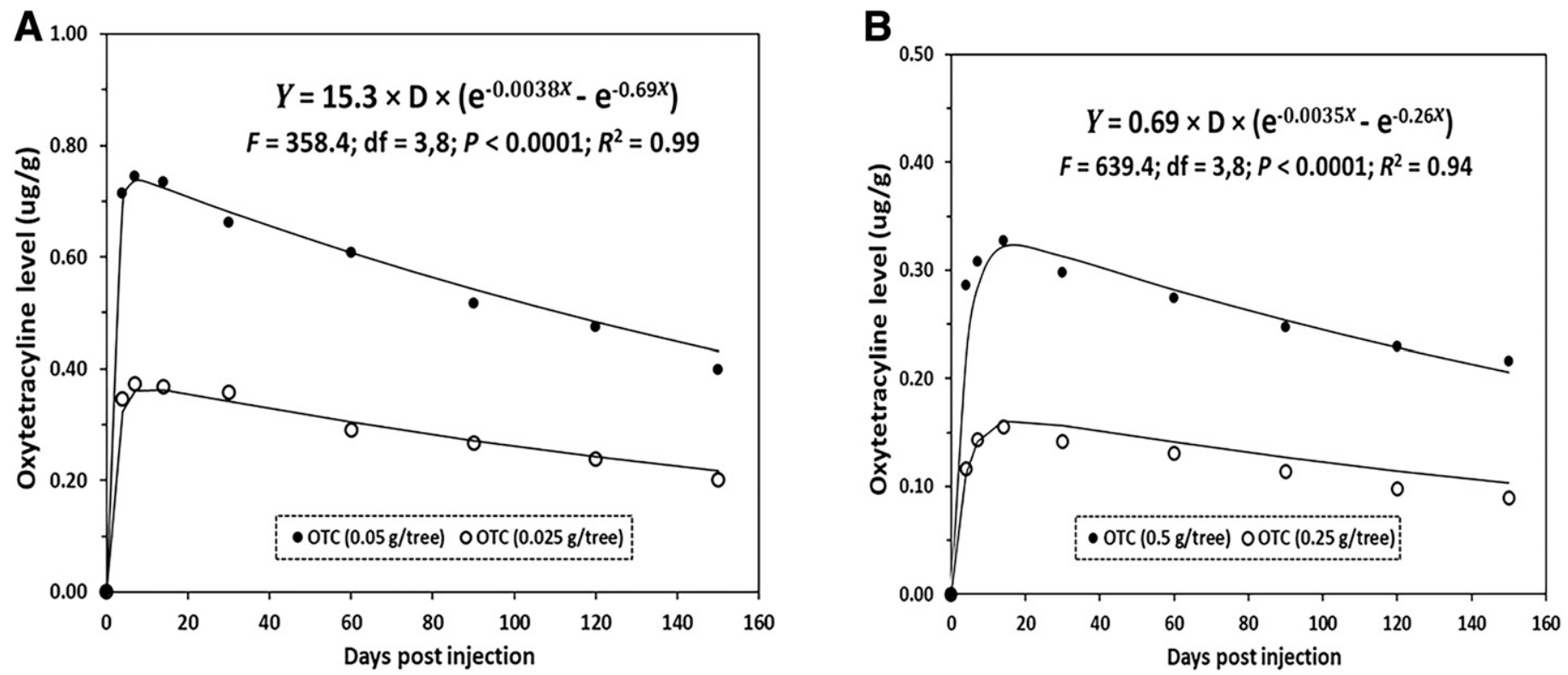

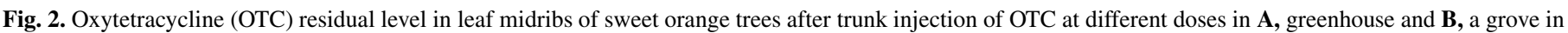

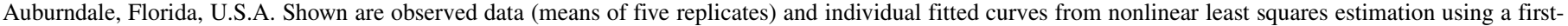
order compartment model, where $Y=$ OTC level, $x=$ time (days postinjection), and $\mathrm{D}=$ dose of OTC injected. df: degree of freedom. 
$\left(F=524.3 ; \mathrm{df}=2,10 ; P<0.0001 ; R^{2}=0.99\right)($ Fig. $4 \mathrm{~A})$. From 4 to 30 DPA, OTC level in leaf tissue exceeded $0.68 \mu \mathrm{g} / \mathrm{g}$, and that achieved a relative level of control for CLas $>99.5 \%$ (Fig. 4A). Based on the model, values for a $95.0 \%$ relative level of control for CLas would require a concentration of $0.58 \mu \mathrm{g} / \mathrm{g}$ of plant tissues for OTC. This concentration was achieved for about 84 days in the greenhouse tests (Fig. 2A).

In the field trial, the concentration of OTC residue in leaf tissues significantly affected the CLas titers in OTC-injected trees. The relationship between the OTC residue concentration in leaf tissue and the detectability of or control level for CLas could be described by a positive sigmoid model (Figs. 3B and 4B). Over the experiment period, although CLas was steadily detected at relatively high levels, higher concentrations of OTC residue were positively associated with greater suppression of CLas population (i.e., higher $\mathrm{Ct}$ mean values from qPCR assays [Fig. 3B] and higher levels of control for CLas [Fig. 4B]). At the injection rate of $0.5 \mathrm{~g}$ per tree, the highest level of control for CLas achieved by OTC was $40 \%$. Based on the prediction of the model, values for negative detection for CLas (i.e., Ct mean values $\geq 36.0$ ) and a $95.0 \%$ relative level of control for CLas would require concentrations of 0.86 and $0.80 \mu \mathrm{g} / \mathrm{g}$ in leaf tissues for OTC, respectively (Figs. 3B and 4B).

MICs of OTC against cultured close relative bacteria of CLas. The results showed that OTC inhibits visible growth of L. crescens, S. meliloti, and A. tumefaciens at $\geq 0.01,0.03$, and

TABLE 2. Oxytetracycline (OTC) residue levels in fruit harvested from Hamlin sweet orange (Citrus sinensis [L.] Osbeck) trees trunk injected with OTC or water in the field trial in Auburndale, Florida, U.S.A., in December $2018^{\mathrm{y}}$

\begin{tabular}{lc}
\hline Treatment & OTC content $(\mu \mathrm{g} / \mathrm{g}$ of fresh tissue $)$ \\
\hline OTC injected at $0.50 \mathrm{~g}$ per tree & $0.038 \pm 0.008 \mathrm{a}^{\mathrm{z}}$ \\
OTC injected at $0.25 \mathrm{~g}$ per tree & $0.018 \pm 0.003 \mathrm{~b}$ \\
Water injected as control & $0.000 \pm 0.000 \mathrm{c}$
\end{tabular}

y Data shown are mean \pm standard deviation of five replicates $(n=5)$.

$\mathrm{z}$ Means followed by different letters are significantly different $\left(F_{2,12}=78.21\right.$; $P<0.0001)$ based on a post hoc means separation using Tukey's honest significant difference test $(\alpha=0.05)$. Testing was conducted at 9 months after injection.
$0.13 \mu \mathrm{g} / \mathrm{ml}$, respectively, compared with the control. Therefore, the MICs of OTC for L. crescens, S. meliloti, and A. tumefaciens were $0.01,0.03$, and $0.13 \mu \mathrm{g} / \mathrm{ml}$, respectively.

\section{DISCUSSION}

Two key elements to consider when utilizing antibiotics to control citrus HLB are the effective concentrations to be established and the retention time of effective concentrations within trees. The establishment of effective concentrations will determine whether CLas can be suppressed by the antibiotics within trees, whereas the period of retention of effective concentrations will determine the timeframe over which CLas is adequately suppressed and HLB is effectively controlled. A major complicating factor is that the thresholds for activity against CLas are not known for all of the antibiotics because of the difficulty in culturing the bacterium in artificial media. In this study, we evaluated the effective concentrations of OTC to suppress or kill CLas in HLB-affected citrus trees for successful HLB control. Our results indicated that the minimum concentrations of OTC required for suppressing CLas population to an undetectable level $(\mathrm{Ct} \geq 36.0)$ in HLB-diseased trees are $\sim 0.68$ and $\sim 0.86 \mu \mathrm{g} / \mathrm{g}$ in leaf tissues (midribs) under greenhouse and field conditions, respectively (Fig. 3). Given the bacteriostatic nature of OTC, the assumed minimum concentrations of OTC required for initial inhibition of CLas growth in planta are $\sim 0.17$ and $\sim 0.215 \mu \mathrm{g} / \mathrm{g}$ of fresh tissue under greenhouse and field conditions, respectively. This is the first study providing important insights into the minimum OTC residue levels in citrus that are required for suppression of CLas population and effective control of citrus HLB under field conditions.

This work, consistent with our previous reports $(\mathrm{Hu}$ and Wang 2016; Hu et al. 2018), indicated that trunk injection of OTC could provide practical control of citrus HLB until longer-term solutions were identified. Furthermore, in this study, significant positive correlations were demonstrated between OTC residue levels in leaves and the control levels for CLas achieved through nonlinear modeling (Figs. 3 and 4). Thus, a minimum concentration of OTC required for suppression of CLas and effective control of HLB was proposed for both greenhouse and field operations. New information gained in this study on the minimum effective concentration of OTC may be
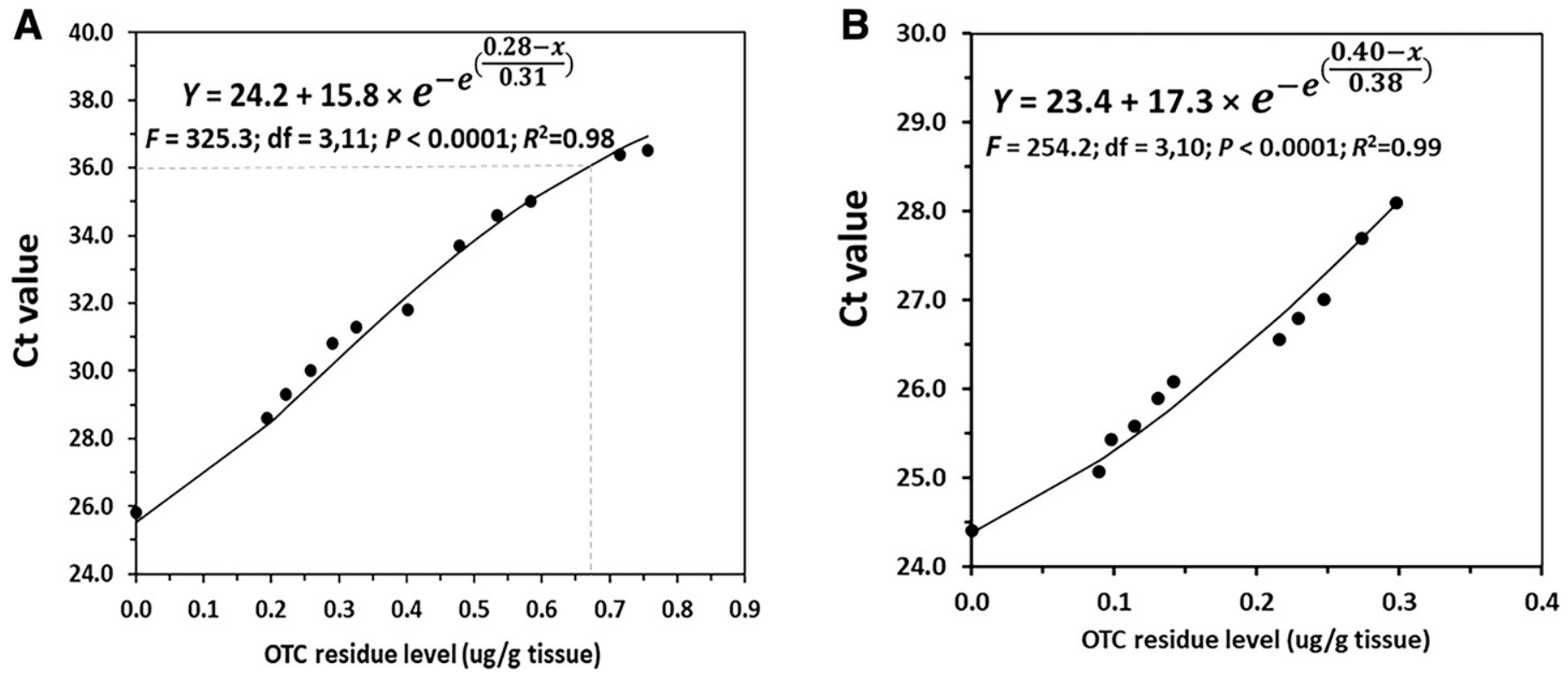

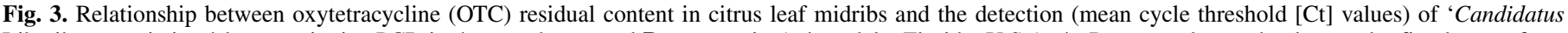

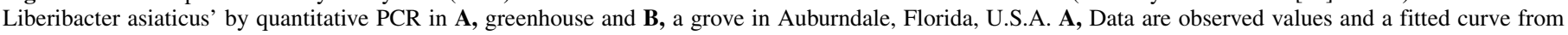

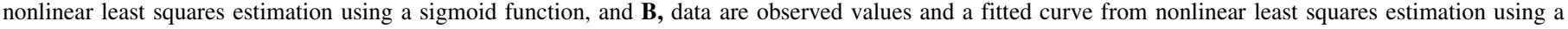
sigmoid model, where $Y=\mathrm{Ct}$ value and $x=$ OTC residue level. df: degree of freedom. 
useful for citrus growers in decision making regarding using OTC for HLB control.

The high level of control of CLas achieved by trunk injection of OTC in this study may result from direct bactericidal effects of OTC on CLas at high concentrations. The MIC of OTC against CLas in artificial media remains to be determined, but the MICs of OTC against $L$. crescens, $S$. meliloti, and A. tumefaciens are 0.01, 0.03, and $0.13 \mu \mathrm{g} / \mathrm{ml}$, respectively (Supplementary Fig. S1 and Table S3). These three bacterial species are the close cultured relatives of CLas (Duan et al. 2009). Therefore, one would expect that the MIC of OTC against CLas in vitro could be within the range from 0.01 to $0.13 \mu \mathrm{g} / \mathrm{ml}$, which is $\sim 5$ to 90 times lower than the estimated 0.68 to $0.86 \mu \mathrm{g} / \mathrm{g}$ of OTC residue in leaf tissues in this study. It is widely recognized that OTC is bacteriostatic against a wide range of gramnegative and gram-positive bacteria, and the minimum bactericidal concentration is more than four times the MIC (Chopra and Roberts 2001). Thus, we may estimate that the in planta MIC of OTC inhibiting the growth CLas in infected trees in the field is $\sim 0.215 \mu \mathrm{g} / \mathrm{g}$, four times lower than the estimated threshold of $0.86 \mu \mathrm{g} / \mathrm{g}$ that is required for suppressing CLas populations to below the detection limit in infected trees. Fujiwara et al. (2018) reported that CLas strain Ishi-1 was not susceptible to OTC in vitro and that the growth of strain Ishi-1 was significantly enhanced in the presence of $1,000 \mu \mathrm{g} / \mathrm{ml}$ of OTC. This is obviously in contrast to our observations. One key contributing factor to this discrepancy is likely the difference between the CLas "strains" used in these two studies. They might be naturally different in susceptibility to OTC. CLas strain Ishi-1 is originally from Japan and lacks prophage regions in its genome, which is genetically different from the Florida "strain" of CLas in our studies (Fujiwara et al. 2018). CLas strain Ishi-1 was also reported to be resistant to seven other antibiotics, including ampicillin, chloramphenicol, kanamycin, rifampicin, streptomycin, and tetracycline at $1,000 \mu \mathrm{g} /$ $\mathrm{ml}$ (Fujiwara et al. 2018), whereas the Florida strain is susceptible to these antibiotics (Zhang et al. 2011). However, the mechanisms of strain Ishi-1 resistant to the antibiotics remain unknown (Fujiwara et al. 2018).

In this work, a first-order compart model appropriately described OTC residue dynamics in leaves of trunk-injected trees (Fig. 2).
Thus, it may be used to estimate the retention of effective concentrations of OTC within treated plants. The results showed that citrus trees rapidly accumulated OTC within the first 2 weeks after trunk injection in the greenhouse and field and reached a maximum level at 7 to 14 days posttreatment (Fig. 4B), suggesting that OTC moved rapidly within citrus trees after trunk injection (Hu and Wang 2016). Our previous studies demonstrated that OTC is uniformly distributed within citrus trees after trunk injection (Hu and Wang 2016). Therefore, the establishment of effective concentrations should be a key determinant to what extent CLas population could be suppressed in treated trees. In this study, peak concentrations of OTC occurred within 2 weeks of application. After the peak concentrations were attained, the measurable levels of OTC began a steady decline in subsequent weeks, but they remained above the thresholds of $0.68 \mu \mathrm{g} / \mathrm{g}$ for suppressing CLas to below the detection limit for up to 4 weeks at the injection rate of $0.05 \mathrm{~g}$ per tree in the greenhouse (Fig. 2A). Regarding the assumed $0.215 \mu \mathrm{g} / \mathrm{g}$ in planta MIC of OTC, the prediction of the established models (Fig. 2) suggested that the OTC residue levels might remain above this threshold for 11 months at the injection rate of $0.05 \mathrm{~g}$ per tree in the greenhouse and for 5 months at the injection rate of $0.5 \mathrm{~g}$ per tree in the field, respectively. Based on these data, the period of retention of effective concentrations of OTC could be about 150 days after a single trunk injection, suggesting a 150 -day period of protection for HLB-diseased trees injected with $0.50 \mathrm{~g}$ per tree of OTC in the field. This is consistent with the notion that repeated application of OTC each year is required to control HLB when applied at lower doses (Bové 2006). If injected at an appropriately high dose that can achieve a residue level sufficient for suppressing CLas populations to below the detection limit, a single application of OTC might be enough for effective control of HLB across growing seasons.

There are concerns of the phytotoxic effects of OTC on citrus plants, especially when it is applied at high concentrations (Zhang et al. 2014). In our previous studies, when injected at $2.0 \mathrm{~g}$ per tree at the beginning stage of early spring flushes, the OTC concentration reached the peak of $1.42 \mu \mathrm{g} / \mathrm{g}$ of leaf tissue and did not show a phytotoxic effect on young, fully expanded leaves or mature leaves
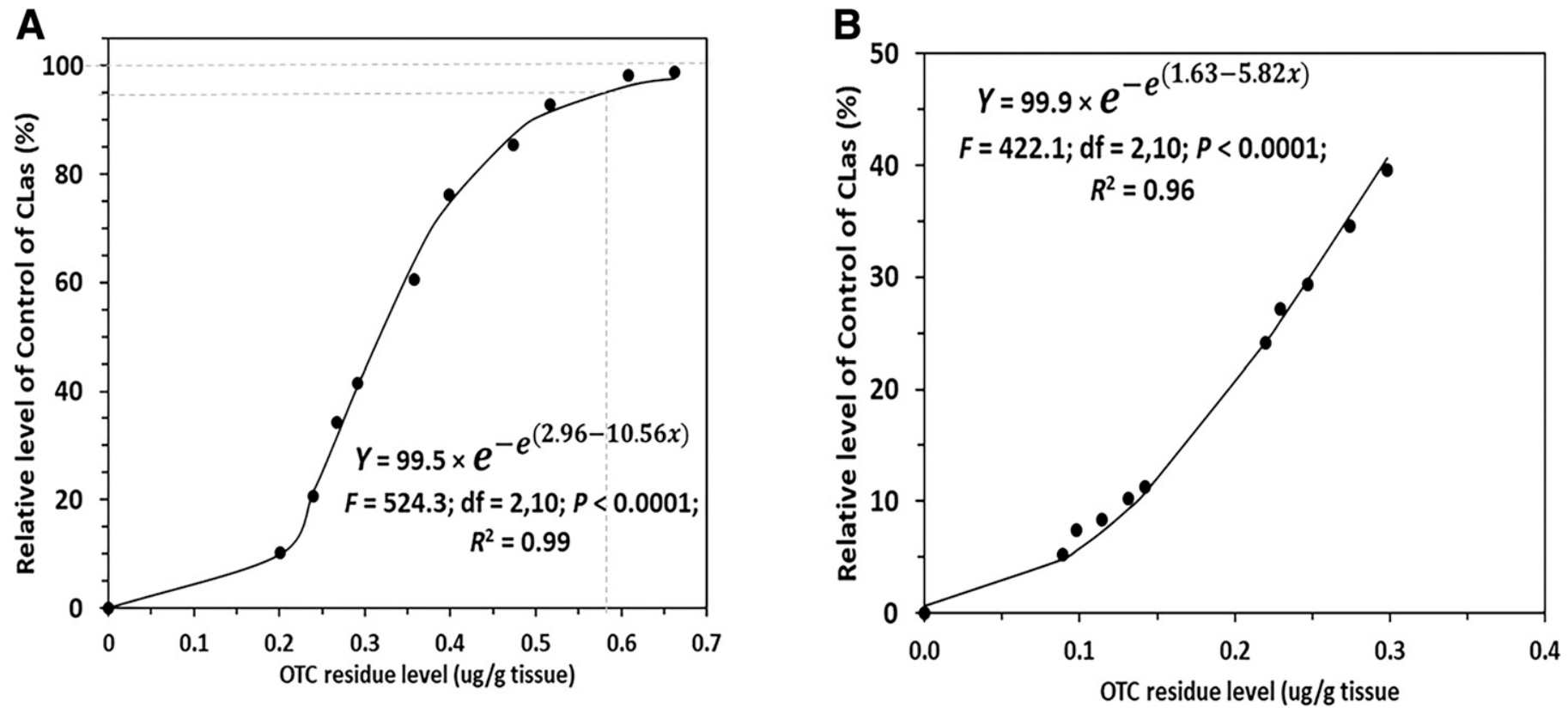

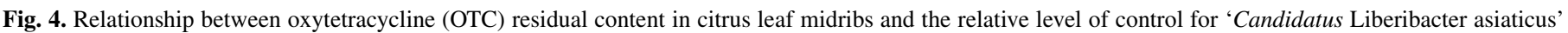

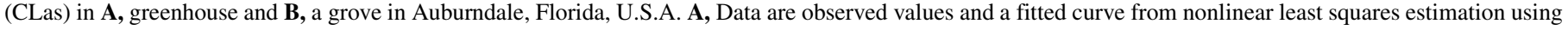

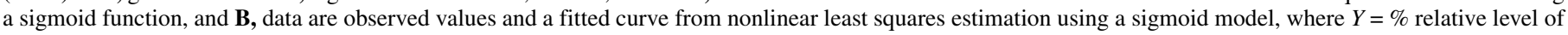

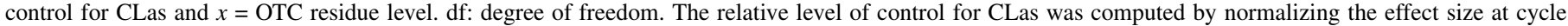
threshold $(\mathrm{Ct})<36.0$ against the effect size at $\mathrm{Ct}=36.0$ achieved by OTC treatment. 
(Hu and Wang 2016). The OTC concentration in new shoots reached the peak of $0.733 \mu \mathrm{g} / \mathrm{g}$ during the first month after injection, and it caused trivial phytotoxicity on new flushes of a young tree, showing brown discoloration and leaf burning (Hu and Wang 2016). In this work, we did not observe a phytotoxic effect of OTC in greenhouse or field trials. In the greenhouse trial, the OTC concentration in mature leaves reached the peak of $0.73 \mu \mathrm{g} / \mathrm{g}$ in the first 2 weeks after injection, and there were no new shoots during this period. In field trial, the OTC peak concentration was $0.33 \mu \mathrm{g} / \mathrm{g}$, over two times lower than the $0.733 \mu \mathrm{g} / \mathrm{g}$ concentration causing trivial phytotoxicity on new flushes reported by $\mathrm{Hu}$ and Wang (2016). Thus, we speculated that minimum concentration of OTC $(0.86 \mu \mathrm{g} / \mathrm{g}$ of tissue) required for suppressing CLas population in planta to an undetectable level $(\mathrm{Ct} \geq 36.0)$ could be achieved in plants without affecting the growth of the tree through trunk injecting a higher dose of OTC by carefully timing to avoid the flushing period in the field. However, this requires additional investigations.

OTC has been used to control citrus HLB in Florida via foliar spray since 2016 under the Emergency Exemptions provisions of Federal Insecticide, Fungicide, and Rodenticide (EPA, Section 18c). OTC spray treatments in various field trials have exhibited inconsistent results (National Academies of Sciences, Engineering, and Medicine 2018). In this study, OTC applications via foliar spray did not show a significant control effect on CLas in treated trees under greenhouse or field conditions. Additionally, we were not able to detect OTC residue in leaves after foliar spray of OTC in the field. This may be because there was no sufficient uptake of OTC after foliar spray application. The epicuticular wax on citrus leaf surface and structural degradation under ultraviolet or visible light (Xuan et al. 2010) might affect OTC uptake. Studies have demonstrated OTC penetration of the cuticle of 1-year-old Valencia after foliar spray with a nonionic surfactant (Vincent et al. 2019). Future studies will need to optimize uptake of OTC after foliar spray by comparing and selecting approximate adjuvants and determine the rate of OTC uptake by citrus trees after foliar spray applications.

The OTC residues in citrus fruit and orange juice need additional evaluation under field conditions. In this study, the highest OTC residue in fruit from the field trial was $0.038 \mu \mathrm{g} / \mathrm{g}$ of fresh tissue at regular harvest season (about 9 months after injection) (Table 2). These residue levels are above the U.S. maximum residue limits of $0.01 \mu \mathrm{g} / \mathrm{g}$ for OTC in or on citrus fruit (EPA 2018). It has been reported that $0.12 \mu \mathrm{g} / \mathrm{g}$ of tetracycline was detected in a fruit after 60 days of injection of tetracycline at the dose of $12,500 \mu \mathrm{g} / \mathrm{ml}$ in $40 \mathrm{ml}$ (i.e., $0.5 \mathrm{~g}$ per tree) (Sruamsiri et al. 2013), and the amount of the antibiotic decreased dramatically after 90 days. The degradation rate of OTC in fruit remains to be determined. Thus, it is critical to further optimize the injection dose and timing for productive trees to achieve reasonable and practical HLB control with acceptable residues during harvest. For new plantings and young, nonbearing trees, OTC residues are likely not concerns, because there is no fruit for harvest. Importantly, new plantings and young, nonbearing trees are more vulnerable than older trees to infection by CLas, and consequently, it is critical to protect those trees from infection by CLas (Gottwald 2010). Therefore, our findings provide useful information about using OTC for effective management of citrus HLB. However, to potentially maximize the effective use and minimize the residue in plant tissues of OTC for HLB management in citrus, we suggest to investigate the effect of injection dose, injection timing, and tree size on OTC residue levels over time after trunk injection in the field.

In summary, this study represents a first attempt at using mathematical modeling to elucidate the in planta minimum effective concentrations of antibiotics within citrus trees for HLB control. Our results provided critical clues about the in planta minimum concentrations of OTC required for a significant reduction of CLas populations in planta and effective control of HLB under greenhouse and field conditions. The finding of this study is a useful starting point to consider for those who use OTC for the control and management of citrus HLB, although additional investigations are required to put it into practice for decision making.

\section{ACKNOWLEDGMENTS}

We thank S. E. Lindow at the University of California, Berkeley and B. H. Singer at the University of Florida for their suggestions with the statistical analysis.

\section{LITERATURE CITED}

Aćimović, S. G., Zeng, Q., Mcghee, G. C., Sundin, G. W., and Wise, J. C. 2015. Control of fire blight (Erwinia amylovora) on apple trees with trunkinjected plant resistance inducers and antibiotics and assessment of induction of pathogenesis-related protein genes. Front. Plant Sci. 6:16.

Andrews, J. M. 2001. Determination of minimum inhibitory concentrations. J. Antimicrob. Chemother. 48:5-16.

Beringer, J. E. 1974. R factor transfer in Rhizobium leguminosarum. J. Gen. Microbiol. 84:188-198.

Blaustein, R. A., Lorca, G. L., and Teplitski, M. 2018. Challenges for managing Candidatus Liberibacter spp. (Huanglongbing disease pathogen): Current control measures and future directions. Phytopathology 108: 424-435.

Bové, J. M. 2006. Huanglongbing: A destructive, newly-emerging, century-old disease of citrus. J. Plant Pathol. 88:7-37.

Chopra, I., and Roberts, M. 2001. Tetracycline antibiotics: Mode of action, applications, molecular biology, and epidemiology of bacterial resistance. Microbiol. Mol. Biol. Rev. 65:232-260.

Clark, K., Franco, J. Y., Schwizer, S., Pang, Z., Hawara, E., Liebrand, T. W. H., Pagliaccia, D., Zeng, L., Gurung, F. B., Wang, P., Shi, J., Wang, Y., Ancona, V., van der Hoorn, R. A. L., Wang, N., Coaker, G., and Ma, W. 2018. An effector from the huanglongbing-associated pathogen targets citrus proteases. Nat. Commun. 9:1718.

da Graça, J. V., Kunta, M., Sétamou, M., Rascoe, J., Li, W., Nakhla, M. K., Salas, B., and Bartels, D. W. 2015. Huanglongbing in Texas: Report on the first detections in commercial citrus. J. Cit. Pathol. https://escholarship.org/ uc/item/99p100ts

Duan, Y., Zhou, L., Hall, D. G., Li, W., Doddapaneni, H., Lin, H., Liu, L., Vahling, C. M., Gabriel, D. W., Williams, K. P., Dickerman, A., Sun, Y., and Gottwald, T. 2009. Complete genome sequence of citrus Huanglongbing bacterium, "Candidatus Liberibacter asiaticus" obtained through metagenomics. Mol. Plant-Microbe Interact. 22:1011-1020.

Dutt, M., Barthe, G., Irey, M., and Grosser, J. 2015. Transgenic citrus expressing an Arabidopsis NPR1 gene exhibit enhanced resistance against huanglongbing (HLB; citrus greening). PLoS One 10:e0137134.

Ehsani, R., Dewdney, M., and Johnson, E. 2016. Controlling HLB with thermotherapy: What have we learned so far? Citrus Ind. 9:26-28.

EPA. 2018. Oxytetracycline; pesticide tolerance. Environmental Protection Agency 40 CFR Part 180. Fed. Regist. 83:233.

Fagen, J. R., Leonard, M. T., McCullough, C. M., Edirisinghe, J. N., Henry, C. S., et al. 2014. Comparative genomics of cultured and uncultured strains suggests genes essential for free-living growth of Liberibacter. PLoS One 9: e84469.

Fujiwara, K., Iwanami, T., and Fujikawa, T. 2018. Alterations of Candidatus Liberibacter asiaticus-associated microbiota decrease survival of $\mathrm{Ca}$. L. asiaticus in in vitro assays. Front. Microbiol. 9:3089.

Gottwald, T. R. 2010. Current epidemiological understanding of citrus huanglongbing. Annu. Rev. Phytopathol. 48:119-139.

Gottwald, T. R, da Graça, J. V., and Bassanezi, R. B. 2007. Citrus huanglongbing: The pathogen and its impact. Plant Health Prog. 8.

Hu, J., Jiang, J., and Wang, N. 2018. Control of citrus huanglongbing via trunk injection of plant defense activators and antibiotics. Phytopathology 108: 186-195.

$\mathrm{Hu}$, J., and Wang, N. 2016. Evaluation of the spatiotemporal dynamics of oxytetracycline and its control effect against citrus Huanglongbing via trunk injection. Phytopathology 106:1495-1503.

Johnson, E. G., Wu, J., Bright, D. B., and Graham, J. H. 2014. Association of 'Candidatus Liberibacter asiaticus' root infection, but not phloem plugging with root loss on huanglongbing-affected trees prior to appearance of foliar symptoms. Plant Pathol. 63:290-298.

Kruse, A., Fattah-Hosseini, S., Saha, S., Johnson, R., Warwick, E., Sturgeon, K., Mueller, L., MacCoss, M. J., Shatters, R. G., Jr., and Heck, M. C. 2017. Combining "omics and microscopy to visualize interactions between the Asian citrus psyllid vector and the Huanglongbing pathogen Candidatus Liberibacter asiaticus in the insect gut. PLoS One 12:e0179531. 
Kumagai, L. B., LeVesque, C. S., Blomquist, C. L., Madishetty, K., Guo, Y., Woods, P. W., Rooney-Latham, S., Rascoe, J., Gallindo, T., Schnabel, D., and Polek, M. 2013. First report of 'Candidatus Liberibacter asiaticus' associated with citrus huanglongbing in California. Plant Dis. 97:283.

Lee, J. A., Halbert, S. E., Dawson, W. O., Robertson, C. J., Keesling, J. E., and Singer, B. H. 2015. Asymptomatic spread of huanglongbing and implications for disease control. Proc. Natl. Acad. Sci. USA 112:7605-7610.

Li, J., Trivedi, P., and Wang, N. 2016. Field evaluation of plant defense inducers for the control of citrus Huanglongbing. Phytopathology 106:37-46.

Li, W., Hartung, J. S., and Levy, L. 2006. Quantitative real-time PCR for detection and identification of 'Candidatus Liberibacter species' associated with citrus huanglongbing. J. Microbiol. Methods 66:104-115.

National Academies of Sciences, Engineering, and Medicine. 2018. A Review of the Citrus Greening Research and Development Efforts Supported by the Citrus Research and Development Foundation: Fighting a Ravaging Disease. The National Academies Press, Washington, DC.

Ngugi, H. K., Lehman, B. L., and Madden, L. V. 2011. Multiple treatment meta-analysis of products evaluated for control of fire blight in the eastern United States. Phytopathology 101:512-522.

Paul, P. A., Lipps, P. E., Hershman, D. E., McMullen, M. P., Draper, M. A., and Madden, L. V. 2007. A quantitative review of tebuconazole effect on Fusarium head blight and deoxynivalenol content in wheat. Phytopathology 97:211-220.

Puttamuk, T., Zhang, S. A., Duan, Y. P., Jantasorn, A., and Thaveechai, N. 2014. Effect of chemical treatments on 'Candidatus Liberibacter asiaticus' infected pomelo (Citrus maxima). Crop Prot. 65:114-121.

Shin, K., Ascunce, M. S., Narouei-Khandan, H. A., Sun, X., Jones, D., Kolawole, O. O., Goss, E. M., and van Bruggen, A. H. C. 2016. Effects and side effects of penicillin injection in huanglongbing affected grapefruit trees. Crop Prot. 90:106-116.

Singerman, A., Burani-Arouca, M., and Futch, S. 2018. The profitability of new citrus plantings in Florida in the era of HLB. HortScience 53:1655-1663.

Sruamsiri, P., Akarapisan, A., and Sringarm, K. 2013. Fang orange, lessons learn from the past, a path to the better future (end). Home Agric. Mag. 37:142-145.

Stansly, P. A., Arevalo, H. A., Qureshi, J. A., Jones, M. M., Hendricks, K., et al. 2014. Vector control and foliar nutrition to maintain economic sustainability of bearing citrus in Florida groves affected by Huanglongbing. Pest Manag. Sci. 70:415-426.

Tansey, J. A., Vanaclocha, P., Monzo, C., Jones, M., and Stansly, P. A. 2017. Costs and benefits of insecticide and foliar nutrient applications to huanglongbing-infected citrus trees. Pest Manag. Sci. 73:904-916.
Tiwari, S., Mann, R. S., Rogers, M. E., and Stelinski, L. L. 2011. Insecticide resistance in field populations of Asian citrus psyllid in Florida. Pest Manag. Sci. 67:1258-1268

Trivedi, P., Sagaram, U. S., Kim, J. S., Brlansky, R. H., Rogers, M. E., Stelinski, L. L., Oswalt, C., and Wang, N. 2009. Quantification of viable 'Candidatus Liberibacter asiaticus' in hosts using quantitative PCR with the aid of ethidium monoazide (EMA). Eur. J. Plant Pathol. 124:553-563.

Vincent, C., Pierre, M., Li, J., and Wang, N. 2019. Implications of heat treatment and systemic delivery of foliar-applied oxytetracycline on citrus physiological management and therapy delivery. Front. Plant Sci. 10:41.

Wang, N. 2019. The citrus huanglongbing crisis and potential solutions. Mol. Plant 12:607-609.

Wang, N., Pierson, E. A., Setubal, J. C., Xu, J., Levy, J. G., Zhang, Y., Li, J., Rangel, L. T., and Martins, J., Jr. 2017a. The Candidatus Liberibacter-host interface: Insights into pathogenesis mechanisms and disease control. Annu. Rev. Phytopathol. 55:451-482.

Wang, N., Stelinski, L. L., Pelz-Stelinski, K. S., Graham, J. H., and Zhang, Y. $2017 \mathrm{~b}$. Tale of the huanglongbing disease pyramid in the context of the citrus microbiome. Phytopathology 107:380-387.

Wang, Z., Yin, Y., Hu, H., Yuan, Q., Peng, G., and Xia, Y. 2006. Development and application of molecular-based diagnosis for 'Candidatus Liberibacter asiaticus', the causal pathogen of citrus huanglongbing. Plant Pathol. 55: 630-638.

Xuan, R. C., Arisi, L., Wang, Q. Q., Yates, S. R., and Biswas, K. C. 2010. Hydrolysis and photolysis of oxytetracycline in aqueous solution. J. Environ. Sci. Health Part B Pestici. Food Contam. Agric. Wastes 45:73-81.

Zhang, M., Guo, Y., Powell, C. A., Doud, M. S., Yang, C., and Duan, Y. 2014. Effective antibiotics against 'Candidatus Liberibacter asiaticus' in HLBaffected citrus plants identified via the graft-based evaluation. PLoS One 9: e111032.

Zhang, M., Powell, C. A., Zhou, L., He, Z., Stover, E., and Duan, Y. 2011. Chemical compounds effective against the citrus huanglongbing bacterium 'Candidatus Liberibacter asiaticus' in planta. Phytopathology 101:1097-1103.

Zhang, M., Yang, C., Powell, C. A., Avery, P. B., Wang, J., Huang, Y., and Duan, Y. 2019. Field evaluation of integrated management for mitigating citrus Huanglongbing in Florida. Front. Plant Sci. 9:1890.

Zou, X., Jiang, X., Xu, L., Lei, T., Peng, A., He, Y., Yao, L., and Chen, S. 2017. Transgenic citrus expressing synthesized cecropin B genes in the phloem exhibits decreased susceptibility to Huanglongbing. Plant Mol. Biol. 93:341-353. 